\title{
EDITORIAL
}

\section{Workplace violence is not part of a doctor's job}

\author{
Barbara Sibbald BJ \\ Cite as: CMAJ 2017 February 6;189:E184. doi: 10.1503/cmaj.170086
}

A patient in a psychiatric unit savagely assaults a doctor in British Columbia, leaving him with severe facial injuries, a broken jaw and other fractures. ${ }^{1}$ This is an extreme case but not an isolated incident. In a survey of 720 primary care physicians in Canada, nearly one-third of respondents had been exposed to aggressive behaviour from a patient $(90 \%)$ or patient's family $(70 \%)$ in the previous month. ${ }^{2}$ Nearly all reported having at least one abusive incident during their career; three-quarters of those were major incidents (e.g., sexual harassment), whereas 39\% were severe (e.g., assault, sexual assault or stalking). ${ }^{3}$

Many physicians, nurses and other health workers experience violence in the workplace. ${ }^{4}$ But why? Survey respondents reported that abusive patients tended to be intoxicated (19\%), repeat abusers (33\%) or had mental illness problems (33\%). ${ }^{2}$ Among abusive family members, $5 \%$ were intoxicated and $14 \%$ were repeat abusers. ${ }^{2}$ Long waiting times, physician shortages, limited resources and stress may also contribute to the problem. ${ }^{2}$

Where a physician works also makes a difference. Canadian physicians working in hospital and psychiatric emergency departments, and after-hours clinics have an increased chance of an abusive encounter, as do clinicians making house calls and those who treat large numbers of patients with mental illness and addiction problems. ${ }^{5}$ A survey of about 700 family physicians in the United Kingdom reported that female and male doctors are at equal risk. ${ }^{6}$ However, it is not known if the same holds true in Canada.

Violence against physicians is associated with increased stress, alcohol consumption and risk of developing mental health problems, including depression, anxiety and suicidal ideation. It may also result in absences, physical problems, quitting or refusing to work in highrisk areas, and compromised patient care. ${ }^{5}$

In the Canadian survey, three-quarters of those who had an abusive encounter in the previous month did not seek help, and 64\% did not report the incident. ${ }^{2}$ More than half were not aware of any policies to protect them. Because some of the perpetrators have psychosis, addiction problems or dementia, physicians may view violence as a part of the patient's medical condition. ${ }^{4}$ Canada's piecemeal approach to the problem - involving unions, health authorities, hospitals and other organizations - may result in a perception of lack of help and underreporting. And that is when violence becomes part of the job.

Part of the solution to reducing workplace violence for physicians lies in research. Most applicable research is old and quantifies the problem rather than exploring causal factors, risk reduction and interventions. ${ }^{4}$ We need standard methods of evaluating the efficacy of protocols for everything from documentation to support, plus preventive measures such as flagging systems and training.
There are many programs that purport to address workplace violence, but few have been validated. One exception is the four-day Omega education and training program that has been delivered to over 47000 Canadian mental health care workers. A study of the intervention showed that it bolstered confidence in dealing with patient aggression, and reduced exposure to minor and serious violence. ${ }^{7}$

Some physicians have suggested amending the Criminal Code of Canada to make it a specific criminal offence to assault health care workers performing their duties, similar to what currently exists for police officers and public transit operators. This was proposed and agreed to in 2015 (and again in 2016) in motions at the Canadian Medical Association's General Council. The association is drafting a letter to the federal minister of justice with suggested wording. At least 30 American states have made it a felony to assault hospital workers. Does this deter attackers? No one has measured it.

National regulatory and professional medical bodies, such as provincial colleges, could also provide leadership in talking about the problem, reducing stigma and encouraging strong action.

Physicians should speak out to their chiefs of staff, their colleges and, when warranted, the police. Workplace violence is not part of their job.

\section{References}

1. Strachan B, Rankin E, Brend Y. Penticton doctor 'savagely assaulted' by psychiatric patient. CBC News 2014 Dec. 8. Available: http://www.cbc.ca/news/canada /british-columbia/penticton-doctor-savagely-assaulted-by-psychiatric-patient-1 .2864468 (accessed 2017 Jan. 23).

2. Miedema BB, Hamilton R, Tatemichi S et al. Monthly incidence rates of abusive encounters for Canadian family physicians by patients and their families. Int. J Family Med 2010;2010:387202.

3. Miedema B, Hamilton R, Lambert-Lanning A, et al. Prevalence of abusive encounters in the workplace of family physicians: a minor, major or severe problem. Can Fam Physician 2010;56:e101-8.

4. Phillips JP. Workplace violence against health care workers in the United States. NEngl J Med 2016;374:1661-9.

5. Miedema B, Maclntyre L, Tatemichi S, et al. How the medical culture contributes to coworker-perpetrated harassment and abuse of family physicians. Ann Fam Med 2012;10:111-7.

6. Elston MA, Gabe J. Violence in general practice: a gendered risk? Sociol Health Illn 2016;38:426-41.

7. Guay S, Goncalves J, Boyer R. Evaluation of an education and training program to prevent and manage patients' violence in a mental health setting: a pretest-post test intervention study. Healthcare (Basel) 2016;4:49.

Competing interests: See www.cmaj.ca/site/misc/cmaj_staff.xhtml

Affiliations: News and Humanities Editor, CMAJ

Correspondence to: CMAJ editor,pubs@cmaj.ca 